\title{
Influence of the Wave Form on the Material Response Delay
}

\author{
J. R. Azinheira, L. Reis, and A. M. R. Ribeiro \\ Instituto Superior Técnico, Universidade de Lisboa, Avenida Rovisco Pais, 1049-001 Lisboa, Portugal \\ Correspondence should be addressed to L. Reis; luis.g.reis@ist.utl.pt
}

Received 14 February 2014; Revised 9 July 2014; Accepted 9 July 2014; Published 24 July 2014

Academic Editor: Valder Steffen Jr.

Copyright (C $2014 \mathrm{~J}$. R. Azinheira et al. This is an open access article distributed under the Creative Commons Attribution License, which permits unrestricted use, distribution, and reproduction in any medium, provided the original work is properly cited.

\begin{abstract}
To model damping effects in structural dynamics, the literature provides a wide range of alternatives. The different models claim different advantages and fields of use where they are useful but, in the end, the compliance of the model with the experimental results, within a given tolerance, is the ultimate criterion for assessing its quality. In the present paper, the behaviour of a simple steel specimen is studied, taking as a focus the time response of the material. Since the harmonic response is well established, the authors propose to submit the specimen to a trapezoidal periodic load and study the behaviour of the response to the load changes. A simple setup was used, using a steel specimen loaded in the linear regime. A carefull test procedure was carried out in order to characterize the dissipation in a quasi-static periodic load. The experimental results show that the response delay to a ramp load depends on the durations of both the previous flat and the ramp itself.
\end{abstract}

\section{Introduction}

The search for a suitable model for the structural hysteresis has been around for almost a century, at least since Kimball and Lovell work [1]. From then up to now, this issue has been addressed by authors, such as Soroka [2], Myklestad [3], Reid [4], Bishop [5], Neumark [6], Lancaster [7], Caughey [8], Crandall [9], Chen [10], Gaul et al. [11], and Ribeiro et al. [12], among many others. The most complete study about the rheological understanding of material damping was proposed by Lazan [13], who describes the phenomenon from the micro scale to some mathematical models. From these works (and many more), the issue of modelling the material damping, even for such common materials as metals working in the so-called linear range, seems far from being settled. In fact, although there are several proposed models, they are handicapped by restrictive conditions for their use that usually imply computationally laborious approaches.

The present work is aimed at providing a contribution, based on experimental tests, to better understand the energy dissipation behaviour of metals under variable loads.

To ensure a better control of the load, the tests were performed with a universal testing machine. The load and deformation time history were experimentally measured. As for the periodic load shape, a trapezoidal wave was used with the flat stage increasingly long, so the next ramp could be considered closer and closer to a ramp after rest, that is, a transient load within a periodic signal. This approach provides a loading of successive ramps with variable length flats; the flats allow for the material to settle down and no memory phenomena would appear in the response to the ramp loads. But experience proved other way, so the study was performed in order to present the behaviour of the specimen. Some parameters to quantify the shape of the load wave and the response of the material were defined. The experimental tests were performed maintaining close control over these parameters. The results were plotted and analysed in order to understand how the length of the flats was affecting the response to the ramp loads.

\section{Methodology}

2.1. Case Study. To study the dissipative behaviour of a common material, a reasonable strategy is to apply a load with some characteristics of the harmonic loads (allowing for the frequency domain approach) and the free vibration (for the time response approach). The waveform is, in this case, crucial and its parameterization shall be used as the input for the analysis of the dissipation phenomena. 
TABLE 1: Chemical compositions of the studied material (in \%wt.).

\begin{tabular}{lccccccccc}
\hline Material & $\mathrm{C}$ & $\mathrm{Si}$ & $\mathrm{Mn}$ & $\mathrm{P}$ & $\mathrm{S}$ & $\mathrm{Cr}$ & $\mathrm{Ni}$ & $\mathrm{Mo}$ & $\mathrm{Cu}$ \\
\hline $42 \mathrm{CrMo} 4$ & 0.39 & 0.17 & 0.77 & 0.025 & 0.020 & 1.10 & 0.30 & 0.16 & 0.21 \\
\hline
\end{tabular}

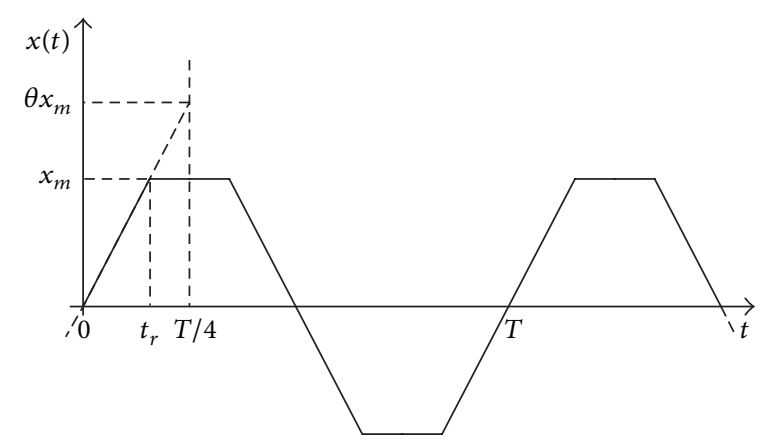

FIgURE 1: Trapezoidal wave showing the amplitude, $x_{m}$, the period, $T$, and the ramp time, $t_{r}$. The origin of the time axis is arbitrary.

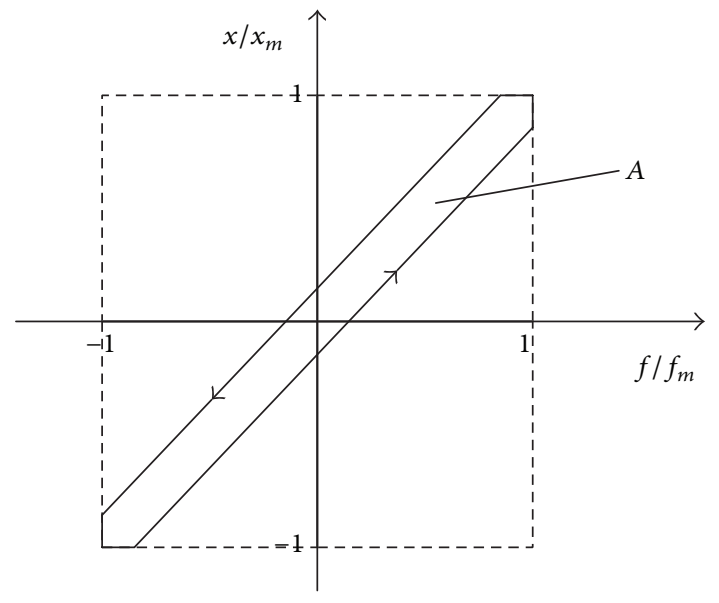

FIgure 2: The area, $A$, of the hysteresis cycle.

TABLE 2: Monotonic and cyclic mechanical properties of the studied material.

\begin{tabular}{lcc}
\hline & & $42 \mathrm{CrMo} 4$ \\
\hline Tensile strength & $\mathrm{Ru}(\mathrm{MPa})$ & 1100 \\
Yield strength & $\mathrm{Rp} 0.2 \%,(\mathrm{MPa})$ & 980 \\
Elongation & $A(\%)$ & 16 \\
Young's modulus & $E(\mathrm{GPa})$ & 206 \\
Cyclic yield strength & $\mathrm{Rp} 0.2 \%, \mathrm{cyclic}$ & 640 \\
Strength coefficient & $(\mathrm{MPa})$ & 1420 \\
Strain hardening exponent & $K^{\prime}(\mathrm{MPa})$ & 0.12 \\
Fatigue strength coefficient & $\sigma f^{\prime}(\mathrm{MPa})$ & 1154 \\
Fatigue strength exponent & $b$ & -0.061 \\
Fatigue ductility coefficient & $\varepsilon f^{\prime}$ & 0.18 \\
Fatigue ductility exponent & $c$ & -0.53 \\
\hline
\end{tabular}

In the present paper, the load was chosen to be a trapezoidal wave function of time, for three reasons as follows.

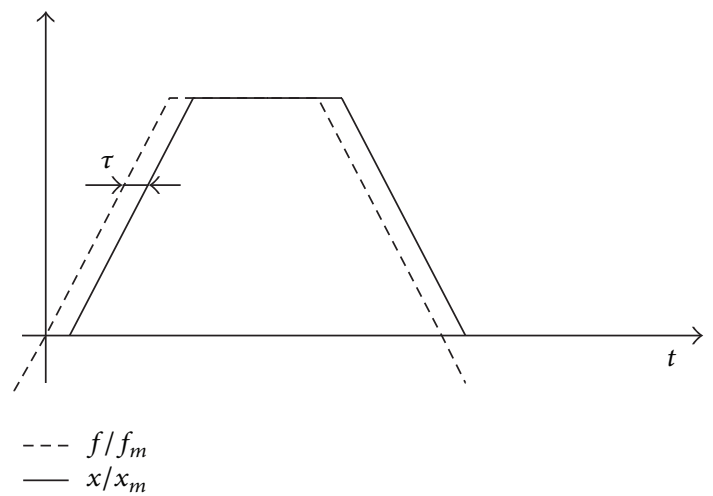

Figure 3: The time delay, $\tau$, between the force, $f$, and the displacement, $x ; f_{m}$ and $x_{m}$ are the force and displacement amplitudes, respectively.

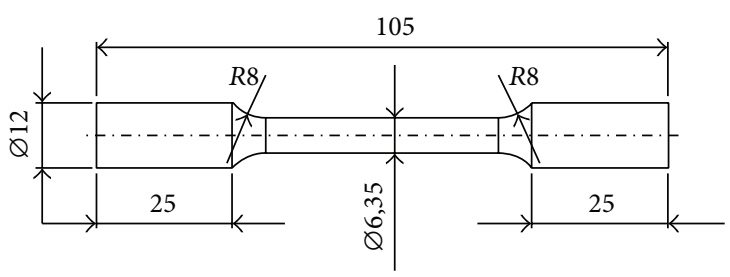

FIGURE 4: Specimen test geometry and dimensions (mm).

(1) It is an intermediate case between the harmonic response, corresponding to an analysis in the frequency domain, and the pure time response, making it possible to draw some comparisons with both cases since.

(2) It provides both ramps and flats, two important cases for studying the response of dynamic systems, before generalising for arbitrary waveforms.

(3) It is a feasible wave for experimental testing, as opposed to ideal rectangular waves or impulses. 


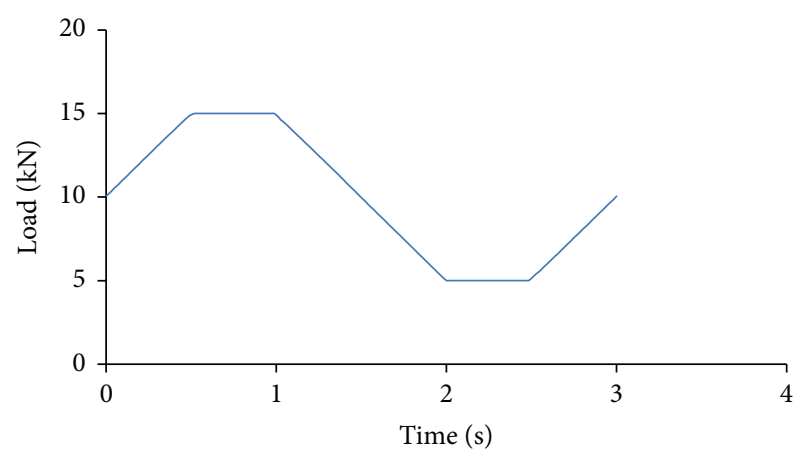

(a)

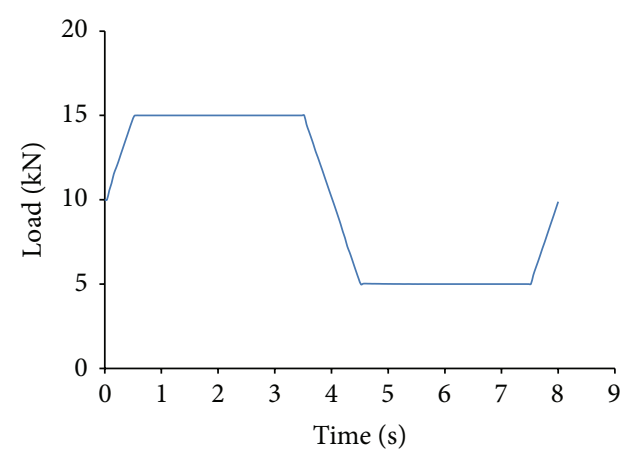

(b)

Figure 5: Examples of applied trapezoidal wave forms. (a) $\theta=1.5, T=3^{\prime \prime}$. (b) $\theta=4, T=8^{\prime \prime}$.

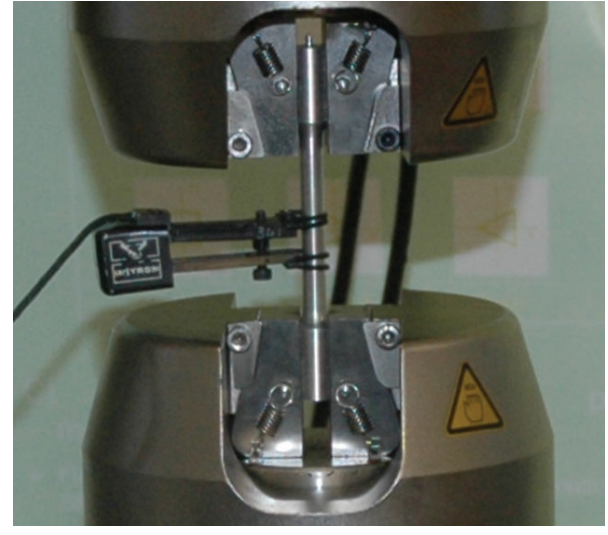

Figure 6: Experimental setup.

TABLE 3: Experimental tests sequence.

\begin{tabular}{lcccc}
\hline $\begin{array}{l}\text { Sequence } \\
\text { of tests }\end{array}$ & $\begin{array}{c}\text { Period } T \\
(\mathrm{~s})\end{array}$ & $\begin{array}{c}\text { Trapezoidal } \\
\text { wave ratio } \theta\end{array}$ & $\begin{array}{c}\text { Rising time } \\
(\mathrm{s})\end{array}$ & $\begin{array}{c}\text { No. of } \\
\text { cycles }\end{array}$ \\
\hline $1^{\circ}$ & 12 & 6 & 0.5 & 20 \\
$2^{\circ}$ & 10 & 2 & 1.25 & 20 \\
$3^{\circ}$ & 8 & 4 & 0.5 & 20 \\
$4^{\circ}$ & 6 & 3 & 0.5 & 25 \\
$5^{\circ}$ & 4 & 2 & 0.5 & 25 \\
$6^{\circ}$ & 3 & 1.5 & 0.5 & 30 \\
$7^{\circ}$ & 6 & 3 & 0.5 & 25 \\
$8^{\circ}$ & 3 & 1.5 & 0.5 & 30 \\
$9^{\circ}$ & 12 & 6 & 0.5 & 20 \\
$10^{\circ}$ & 8 & 4 & 0.5 & 20 \\
$11^{\circ}$ & 10 & 2 & 1.25 & 20 \\
$12^{\circ}$ & 4 & 2 & 0.5 & 25 \\
\hline
\end{tabular}

The frequency of the periodic wave was chosen so that a quasi-static regimen is achieved during each cycle, allowing for the vanishing of the transient during each ramp and each flat, while the periodic character of the load still permits the use of a manageable number of terms of the Fourier series to compute the forced response. On the other hand, it is a simple enough case to study, as long as the amplitude of the wave is kept well within the linear range, as was the case.

2.2. Control Parameters. The material damping for metals is usually quite small and since the wave periods were relatively long, the transient response at the beginning of each slice (ramp or flat) is hardly visible when plotting the complete response, so some specially selected parameters shall be used to describe the relations between load and response, both assuming the trapezoidal form.

(1) The trapezoidal wave ratio, $\theta$, (1) is defined as the ratio between the heights of the evolving triangle and the top of the trapeze (flat) (see Figure 1):

$$
\theta=\frac{T}{4 t_{r}}
$$

(2) The area, $A$, of the hysteretic cycle is a measure of the lost energy per cycle (Figure 2).

(3) The time delay, $\tau$, between the load ramp and the response ramp (Figure 3).

For pure trapezoidal curves, the area of the hysteresis unit cycle is easily computed and for a small delay it is directly proportional to the time delay:

$$
A=\frac{4 \tau}{t_{r}}\left(1-\frac{\tau}{4 t_{r}}\right) \approx \frac{4 \tau}{t_{r}}
$$

The analysis shall describe the influence of frequency and the trapezoidal ratio on both area $A$ and time delay $\tau$, both related to the energy dissipation.

\section{Experimental Tests}

3.1. General Consideration. To allow for a long flat in the trapezoidal wave, it would not be practical to use a vibrating system; but since the aim is to consider only the elastic and dissipative forces, a universal testing machine was used to apply controlled loads with the required profile. 

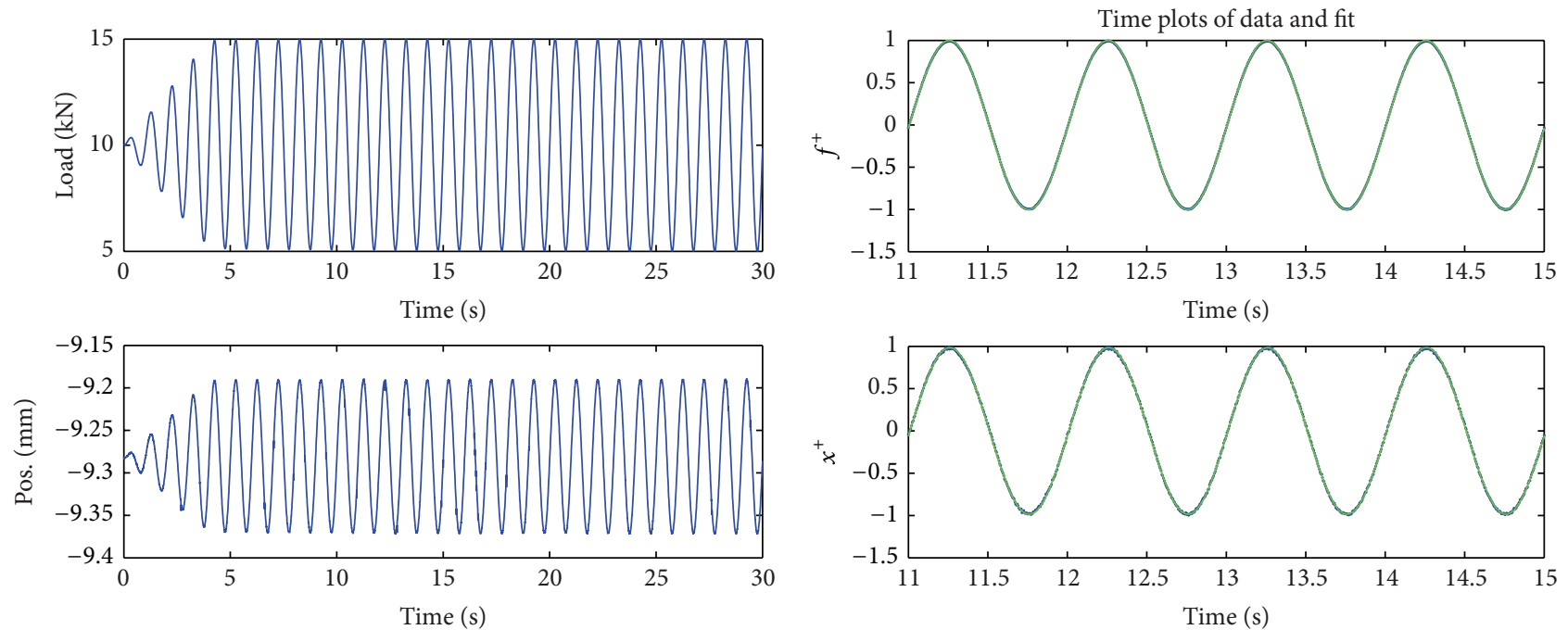

(a)

(b)
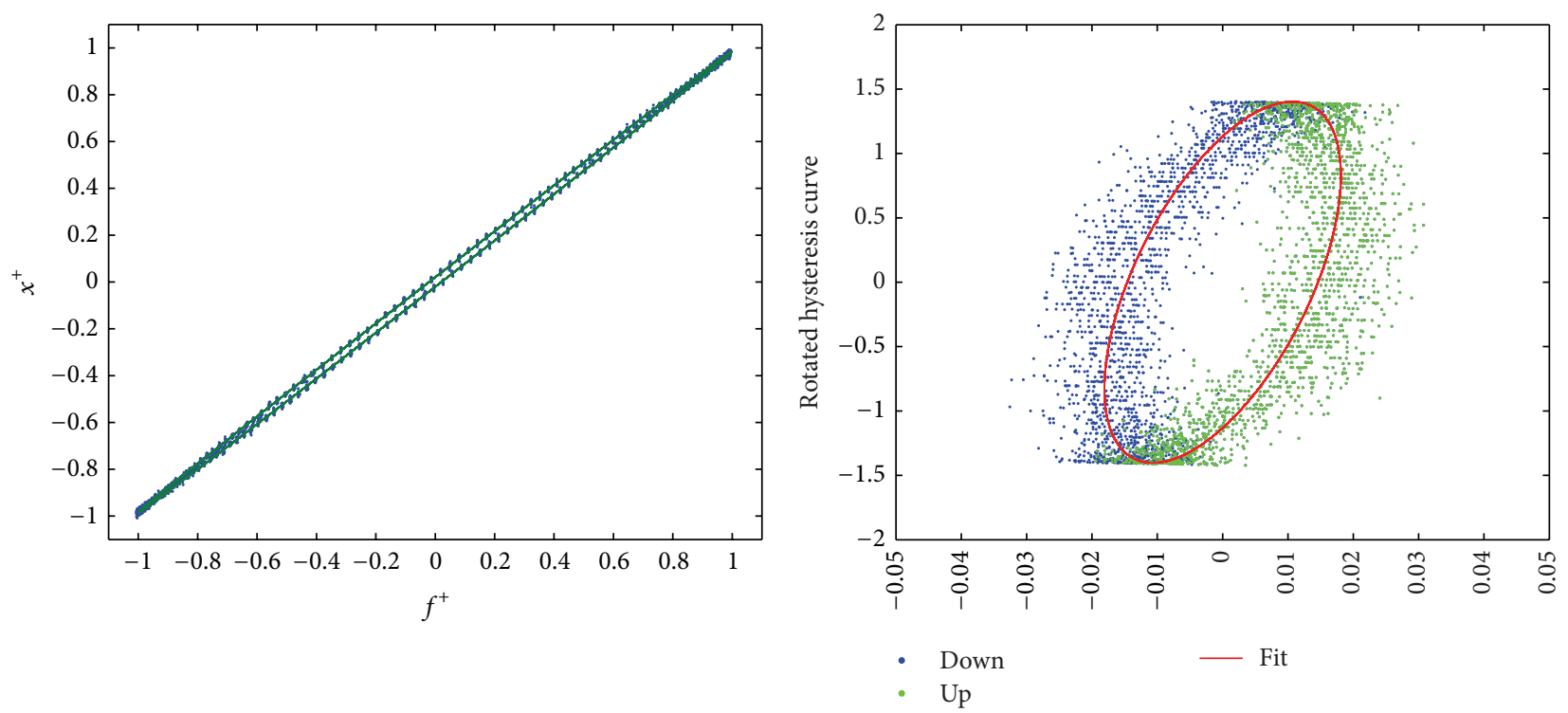

(c)

(d)

FiguRE 7: Sine wave load. (a) Raw data: time histories for load (above) and displacement (below). (b) Selected cycles: raw data and fit. (c) Hysteresis plot: normalized displacement versus normalized force. (d) Rotated hysteresis plot: measured points for increasing (green) and decreasing (blue) force and fitting curve (red).

3.2. Specimen Used. The material used in this work is the high strength steel $42 \mathrm{CrMo} 4$. The chemical composition and monotonic and cyclic mechanical properties are shown in Tables 1 and 2, respectively. The geometry and dimensions of the specimen used in the testing program are shown in Figure 4 . Specimens were polished before testing.

3.3. Test Procedure. In order to study the energy dissipation of this material, cyclic stress-strain tests in tension were carried out. Six different trapezoidal wave forms, as the examples shown in Figure 5, were applied in the experiments. To check the influence of the trapezoidal wave form, tests were first performed, first with a decreasing period, with a constant rise time $t_{r}=0.5^{\prime \prime}$, except for the second test where $t_{r}=1.25^{\prime \prime}$, and then the tests were repeated in a random order: the sequence may be seen in Table 3.

Tests of uniaxial cyclic tension were performed in a servohydraulic machine Instron 8874 ; a strain gage was used to measure the strains along the cycles (see Figure 6). Test conditions were as follows: $R=1 / 3$ and $F_{\max }=15.0 \mathrm{kN}$ in load control at room temperature in laboratory air. The tests were performed with a nonzero average force to avoid any possible equipment borne noise due to the changes of sign.

3.4. Experimental Data Postprocessing. The following procedure was applied for the analysis of the experimental data.

For each test, a set of three time histories was recorded, with load, overall displacement as measured by the LVDT 

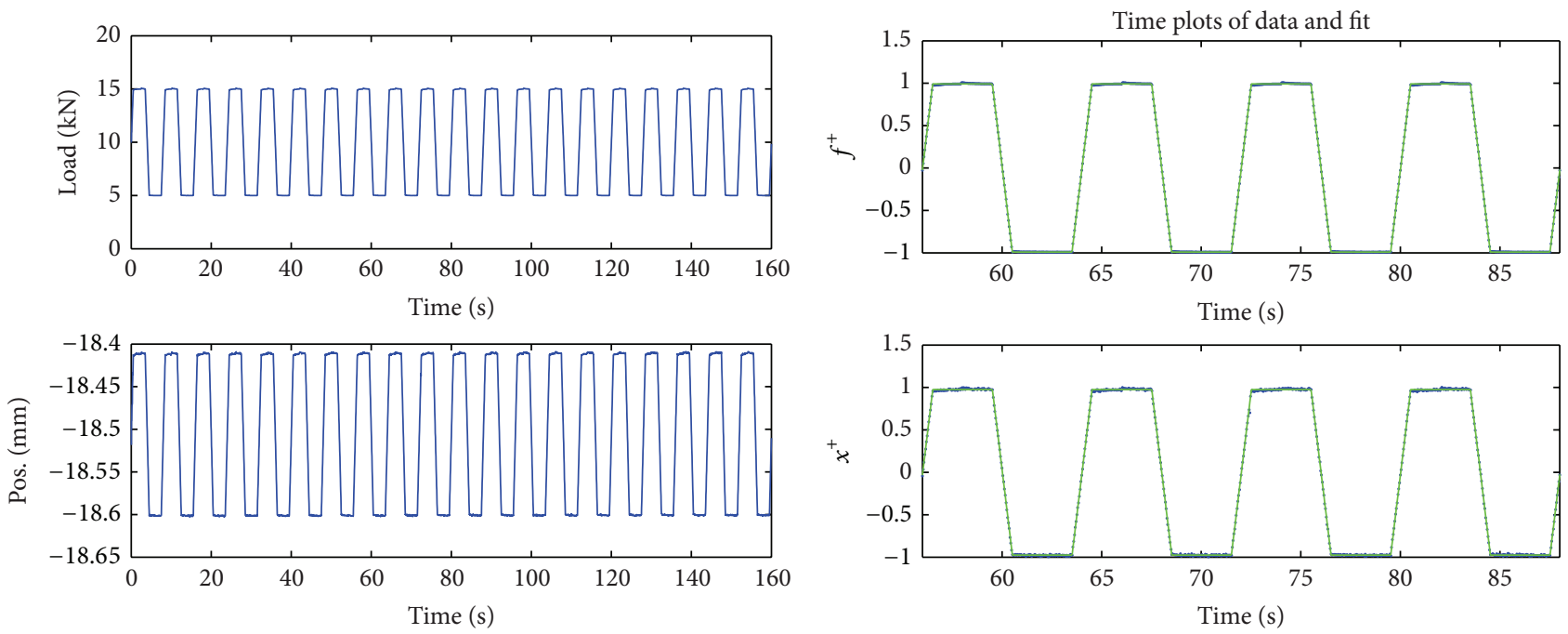

(a)

(b)
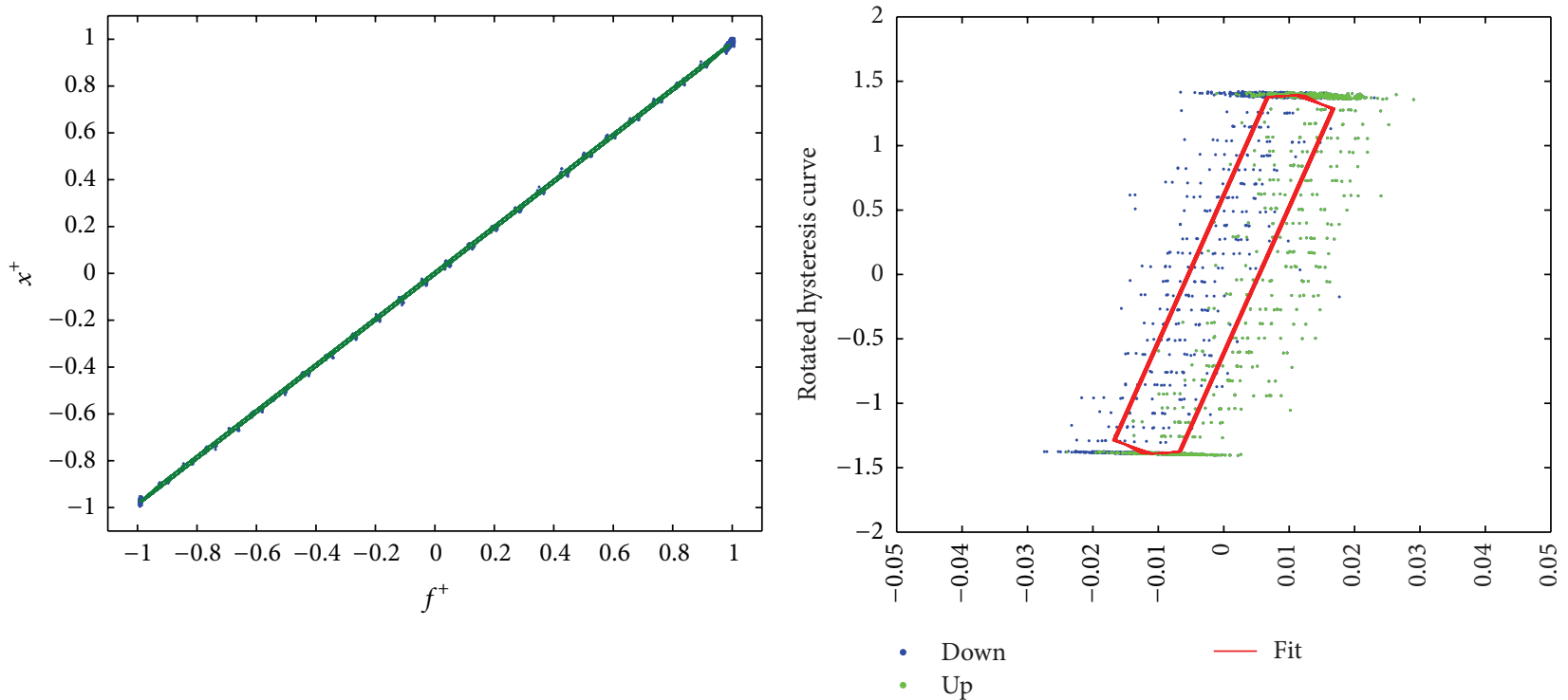

(c)

(d)

FIgURE 8: Trapezoidal wave $\left(\theta=4, t_{r}=0.5 \mathrm{sec}\right.$.). (a) Raw data: time histories for load (above) and displacement (below). (b) Selected cycles: raw data and fit. (c) Hysteresis plot: normalized displacement versus normalized force. (d) Rotated hysteresis plot: measured points for increasing (green) and decreasing (blue) force and fitting curve (red).

sensor and strain as measured by the strain gage. The analysis then went through the following steps.

(1) Plot raw time curves, for test validation or to detect any undesired occurrence.

(2) Select a sequence of 4 to 8 cycles where the signal is stable, namely, avoiding the initial part where the periodic signal may not be fully settled.

(3) Both time curves are normalized to unity, subtracting the offset (average for an integer number of periods) and dividing by the wave amplitude to illustrate this, in the case of the load curve:

$$
\left\{\begin{array}{l}
\bar{f}=\operatorname{mean}(f) \\
f_{m}=\frac{1}{2}(\max (f)-\min (f))
\end{array} \Longrightarrow f^{+}=\frac{f-\bar{f}}{f_{m}} .\right.
$$

(4) Compute a fitting curve of each of the time histories with a normalized trapezoidal curve-here the problem was expressed as a nonlinear least squares problem solved using Matlab "lsqcurvefit" function.

(5) Plot the normalized hysteresis curves, $f^{+}\left(x^{+}\right)$, and compute the area $A$ of the hysteretic cycle. 

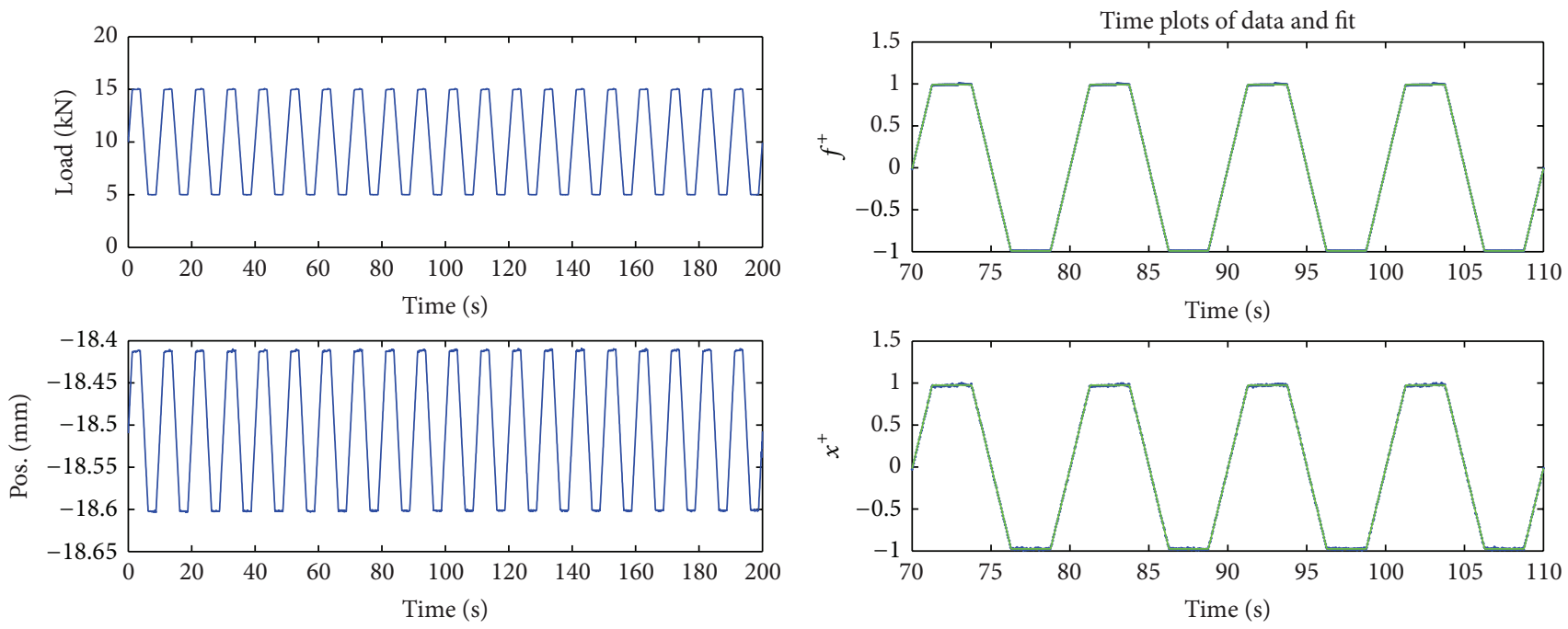

(a)
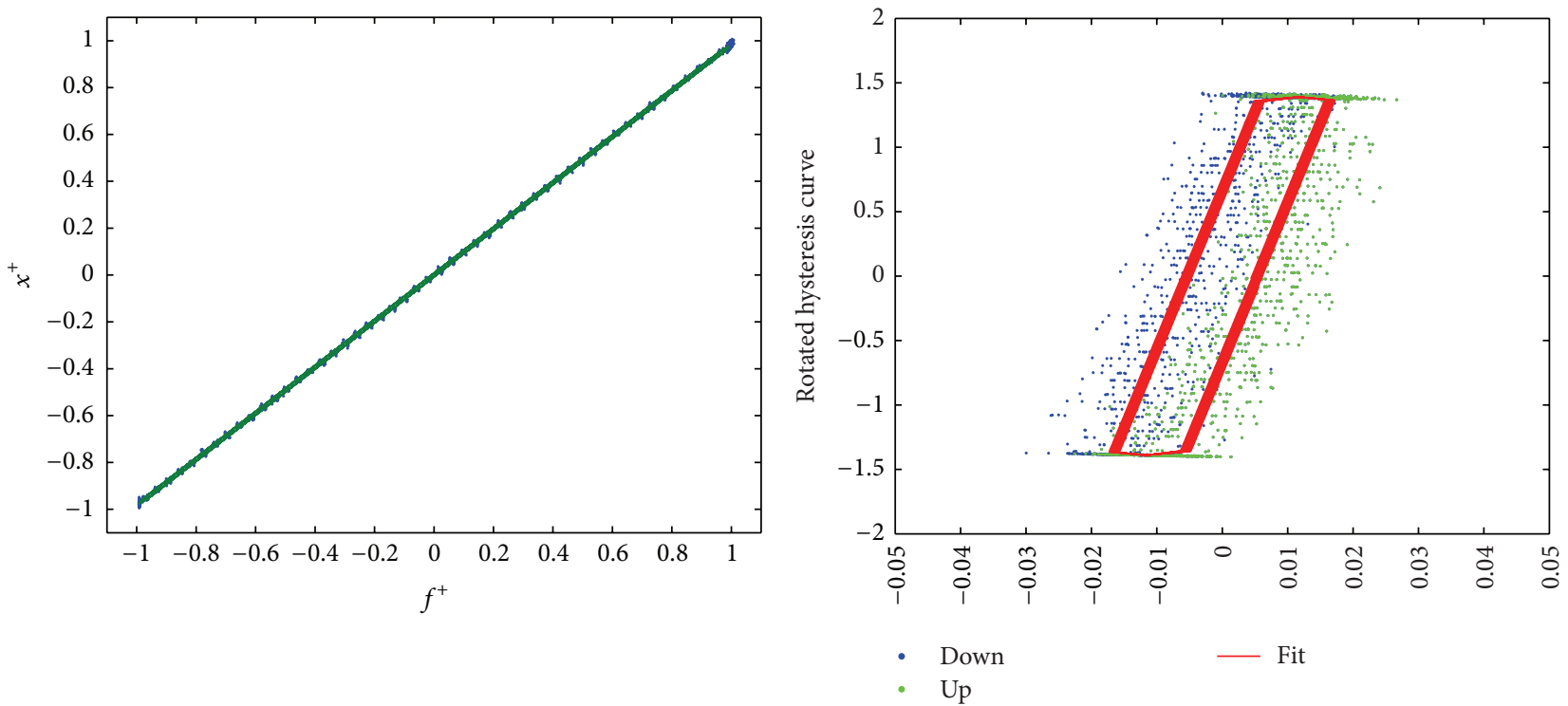

(c)

(d)

Figure 9: Trapezoidal wave $\left(\theta=2, t_{r}=1.25 \mathrm{sec}\right.$.). (a) Raw data: time histories for load (above) and displacement (below). (b) Selected cycles: raw data and fit. (c) Hysteresis plot: normalized displacement versus normalized force. (d) Rotated hysteresis plot: measured points for increasing (green) and decreasing (blue) force and fitting curve (red).

(6) Plot the rotated hysteresis curve: in order to increase visibility, the former plot is rotated by $45^{\circ}$ and the abscissa scale is then changed so that the points of increasing load can be differentiated from the points where it is decreasing.

(7) Compute time delay $\tau$ and the area $A_{f}$ of the hysteresis cycle using the fitted trapezoidal time curves.

The results from the full sequence of sets are finally obtained as the evolution of time delay or hysteretic areas as functions of period, trapezoidal ratio, and rising time.

Since, for pure trapezoidal waves, the area is approximately proportional to the time delay $\left(A \approx 4 \tau / t_{r}\right)$, the time delay from the area computed from the raw data, $\tau \approx A t_{r} / 4$, may also be estimated.

3.4.1. Illustrative Sine Example. In order to illustrate and validate the procedure, a sine example is first used and its results are presented in Figure 7.

Here the strain gage output is taken as the displacement measurement for the hysteresis plots.

Despite some scattering mostly due to measurement noise, the rotated hysteretic plot exhibits an elliptic form as predicted by the theory. The values for the area are 0.0645 (computed directly from raw data) and 0.0644 (computed from fitting ellipsis) which are in good agreement. 


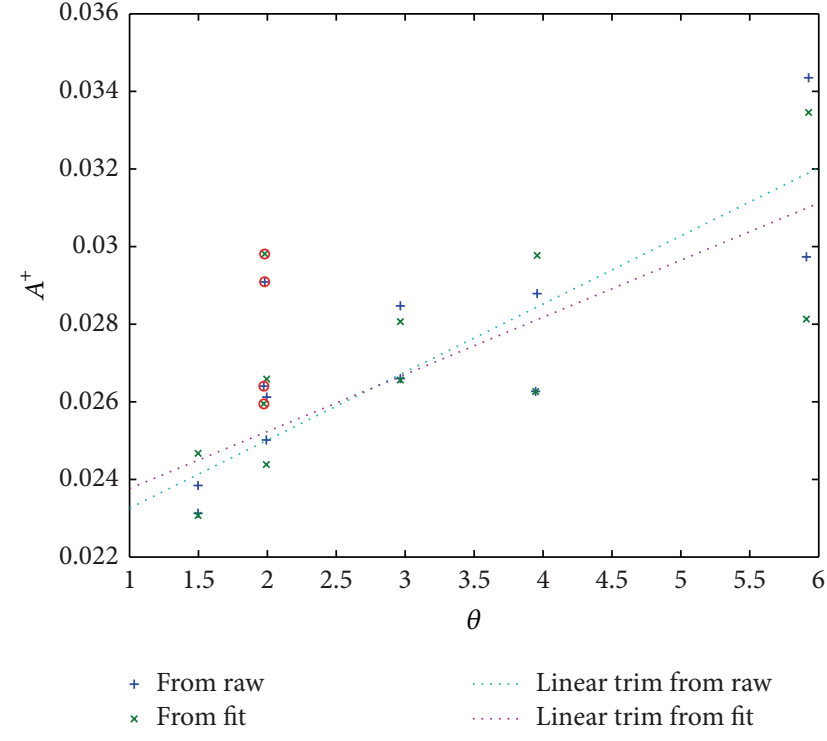

(a)

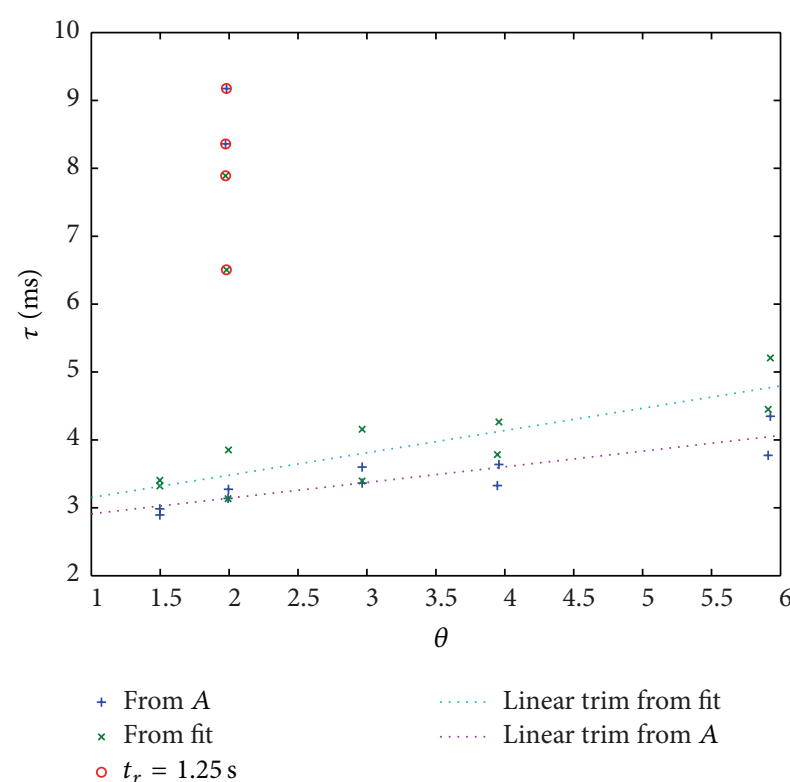

(b)

Figure 10: Hysteresis cycle area (a) and time delay (b) versus trapezoidal wave ratio.

TABLE 4: Experimental results.

\begin{tabular}{lcccccc}
\hline Sequence & $T[\mathrm{~s}]$ & $\theta$ & $t_{r}[\mathrm{sec}]$ & $A$ & $A_{f}$ & $\tau[\mathrm{ms}]$ \\
\hline $1^{\circ}$ & 12 & 5.9 & 0.51 & 0.0344 & 0.0335 & 5.21 \\
$2^{\circ}$ & 10 & 2.0 & 1.26 & 0.0291 & 0.0298 & 6.50 \\
$3^{\circ}$ & 8 & 4.0 & 0.51 & 0.0288 & 0.0298 & 4.27 \\
$4^{\circ}$ & 6 & 3.0 & 0.51 & 0.0285 & 0.0281 & 3.40 \\
$5^{\circ}$ & 4 & 2.0 & 0.50 & 0.0261 & 0.0266 & 3.85 \\
$6^{\circ}$ & 3 & 1.5 & 0.50 & 0.0238 & 0.0247 & 3.41 \\
$7^{\circ}$ & 6 & 3.0 & 0.51 & 0.0266 & 0.0266 & 4.16 \\
$8^{\circ}$ & 3 & 1.5 & 0.50 & 0.0231 & 0.0231 & 3.32 \\
$9^{\circ}$ & 12 & 5.9 & 0.51 & 0.0291 & 0.0281 & 4.45 \\
$10^{\circ}$ & 8 & 3.9 & 0.51 & 0.0263 & 0.0263 & 3.78 \\
$11^{\circ}$ & 10 & 2.0 & 1.27 & 0.0264 & 0.0259 & 7.89 \\
$12^{\circ}$ & 4 & 2.0 & 0.50 & 0.0250 & 0.0244 & 3.14 \\
\hline
\end{tabular}

This case validates the experimental setup for the following cases.

3.4.2. Trapezoidal Example with $t_{r}=0.5 \mathrm{sec}$. In order to illustrate the procedure for the trapezoidal case, first consider the trapezoidal wave $\mathrm{Nr} 2$ from the above sequence $(\theta=4$, $t_{r}=0.5 \mathrm{sec}$. , Figure 8 ).

If compared with the sine case, the increasing and decreasing parts of the hysteretic curve are not so clearly apart and partly overlay due to high noise level.

3.4.3. Trapezoidal Example with $t_{r}=1.25 \mathrm{sec}$. The next example is the trapezoidal wave $\mathrm{Nr} 3\left(\theta=2, t_{r}=1.25 \mathrm{sec}\right.$., Figure 9).
3.5. Analysis of the Full Sequence. Table 4 presents the results from the fitting process $\left(A_{f}\right.$ and $\left.\tau\right)$ as well as the area $A$ computed with the raw data.

(1) The fitting may first be validated.

(2) Both the trapezoidal ratio $\theta$ and the rising time $t_{r}$ are well recovered from the fitted curves.

(3) Despite the noise level, the areas from raw data and fitted curves are in very good agreement, with values ranging from 0.023 to 0.034 .

The estimated time delay varies between 3.14 and $7.89 \mathrm{~ms}$.

For those tests where the rising time is $t_{r}=0.5^{\prime \prime}$ (all except tests $\mathrm{Nr} 2$ and $\mathrm{Nr} 11$ ), the load ramp is similar and nevertheless the time delay is not constant and the length of 
the flat, as reflected by $\theta$, results in a trend of increased delay and area values.

In Figure 10, area and time delay are plotted against $\theta$, either using the raw data or using the parameters from the fitted curves.

Note that

(1) despite some scattering due to a reduced signal to noise ratio, both parameters are clearly increasing with the trapezoidal ratio $\theta$;

(2) area and time delay are also sensitive to the rising time $t_{r}$.

\section{Conclusions}

Tests were planned with a simple setup but carefully performed in order to characterize the dissipation in a periodic quasi-static trapezoidal load.

Experimental results show that both the time delay and the dissipation area are depending on the load frequency and rising time. More precisely, for a constant rising time, the response time delay is affected by the flat length between ramps, exhibiting a kind of memory effect.

The material response, as measured by the response time delay, depends on the steepness of the ramp but the material seems to exhibit a memory effect in circumstances that would not usually be taken into account as well, something that invites for further research in this area.

\section{Conflict of Interests}

The authors declare that there is no conflict of interests regarding the publication of this paper.

\section{References}

[1] A. L. Kimball and D. E. Lovell, "Internal friction in solids," Physical Review, vol. 30, no. 6, pp. 948-959, 1927.

[2] W. W. Soroka, "Note on the relations between viscous and structural damping coefficients," Journal of the Aeronautical Sciences, vol. 16, pp. 409-410, 1949.

[3] N. O. Myklestad, "The concept of complex damping," Journal of Applied Mechanics, vol. 19, p. 284, 1952.

[4] T. J. Reid, "Free vibration and hysteretic damping," Journal of the Royal Aeronautical Society, vol. 60, article 283, 1956.

[5] R. E. D. Bishop, "The treatment of damping forces in vibration theory," Journal of the Royal Aeronautical Society, vol. 59, p. 738, 1955.

[6] S. Neumark, "Concept of complex stiffness applied to problems of oscillation with viscous and hysteretic damping," Tech. Rep. 3269, Aero Research Council R\&M, 1957.

[7] P. Lancaster, "Free vibration and hysteretic damping," Journal of the Royal Aeronautical Society, vol. 64, p. 229, 1960.

[8] T. K. Caughey, "Vibration of dynamic systems with linear hysteretic damping, linear theory," in Proceedings of the 4th U.S. National Congress of Applied Mechanics, pp. 87-97, 1962.

[9] S. H. Crandall, "The role of damping in vibration theory," Journal of Sound and Vibration, vol. 11, no. 1, pp. 3-18, 1970.
[10] L. Y. Chen, J. T. Chen, C. H. Chen, and H.-K. Hong, "Free vibration of a SDOF system with hysteretic damping," Mechanics Research Communications, vol. 21, no. 6, pp. 599-604, 1994.

[11] L. Gaul, S. Bohlen, and S. Kempfle, "Transient and forced oscillations of systems with constant hysteretic damping," Mechanics Research Communications, vol. 12, no. 4, pp. 187-201, 1985.

[12] A. M. R. Ribeiro, N. M. M. Maia, J. M. M. Silva, M. Freitas, and L. Reis, "Free vibration response using the constant hysteretic damping model," in Proceedings of the of the XI International Conference on Vibration Engineering, pp. 65-70, Timisoara, Romania, 2005.

[13] B. J. Lazan, Damping of Materials and Members in Structural Mechanics, Pergamon Press, Oxford, UK, 1968. 

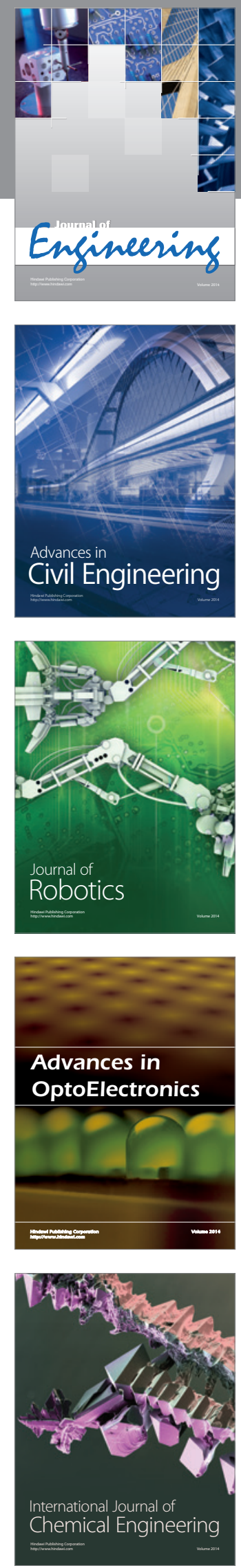

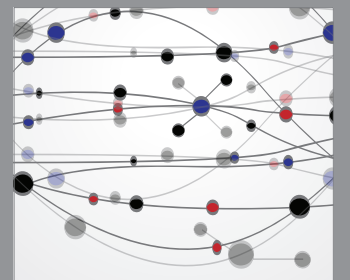

The Scientific World Journal
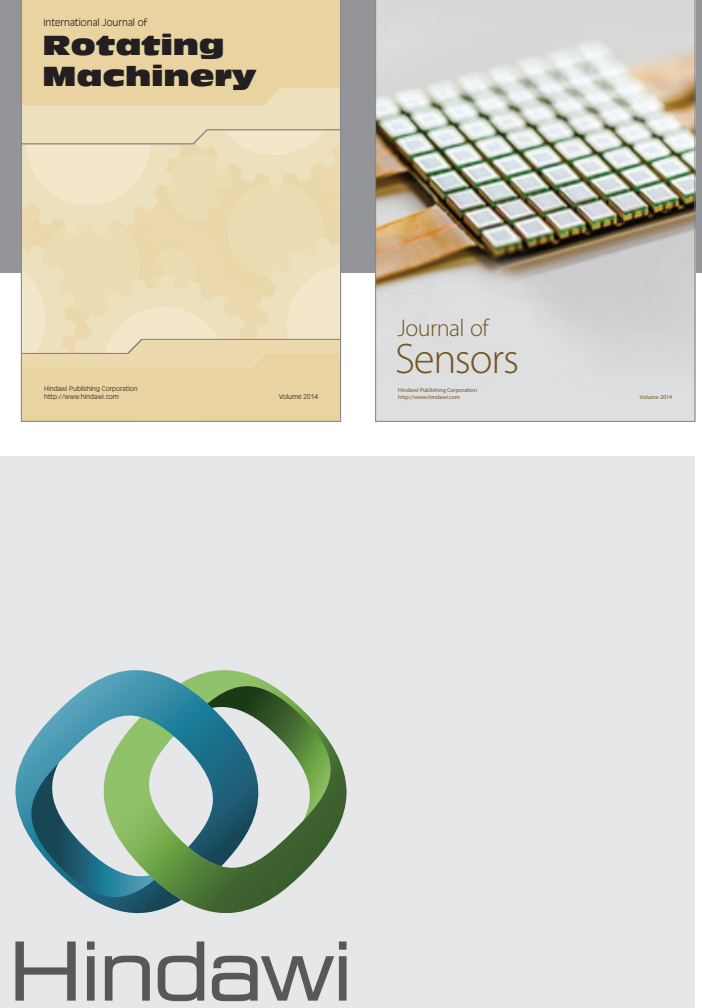

Submit your manuscripts at http://www.hindawi.com
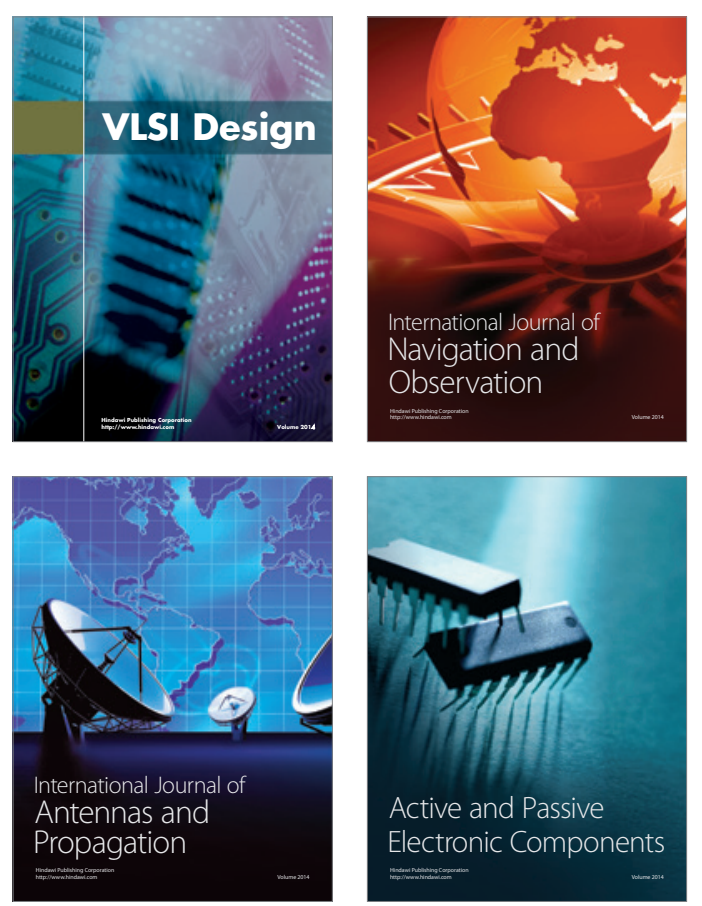
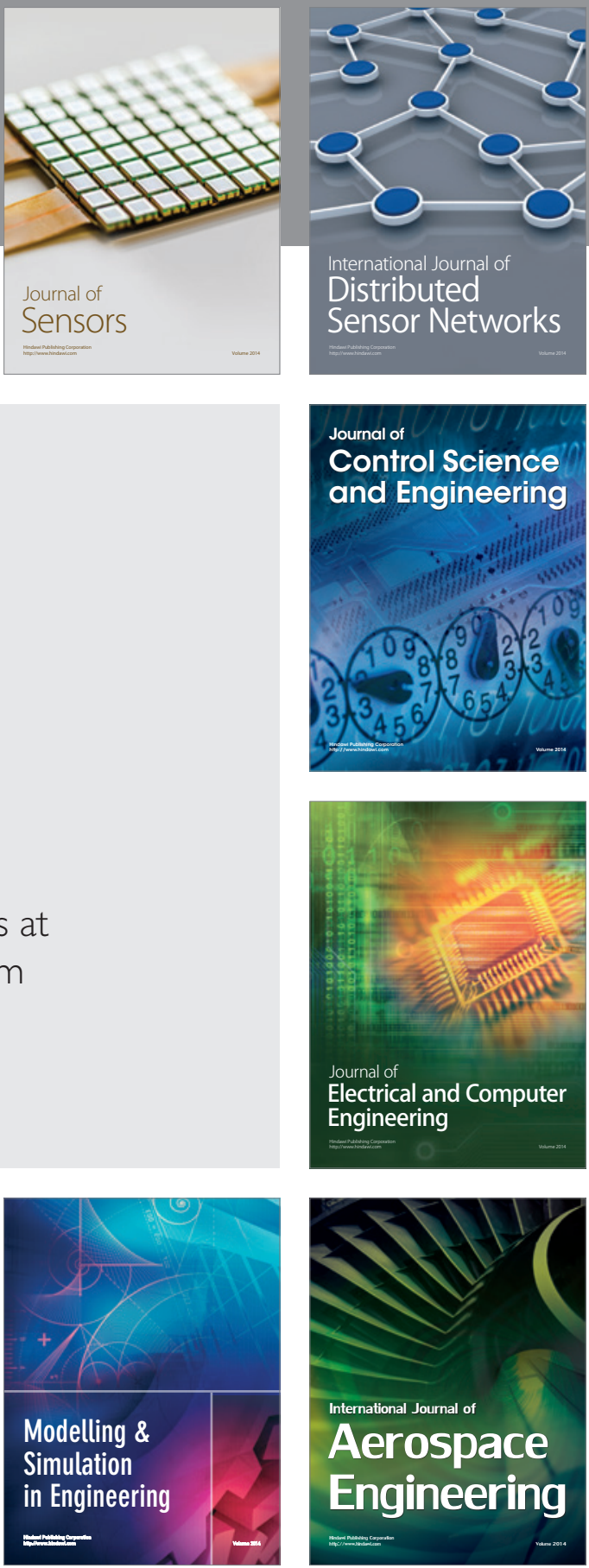

Journal of

Control Science

and Engineering
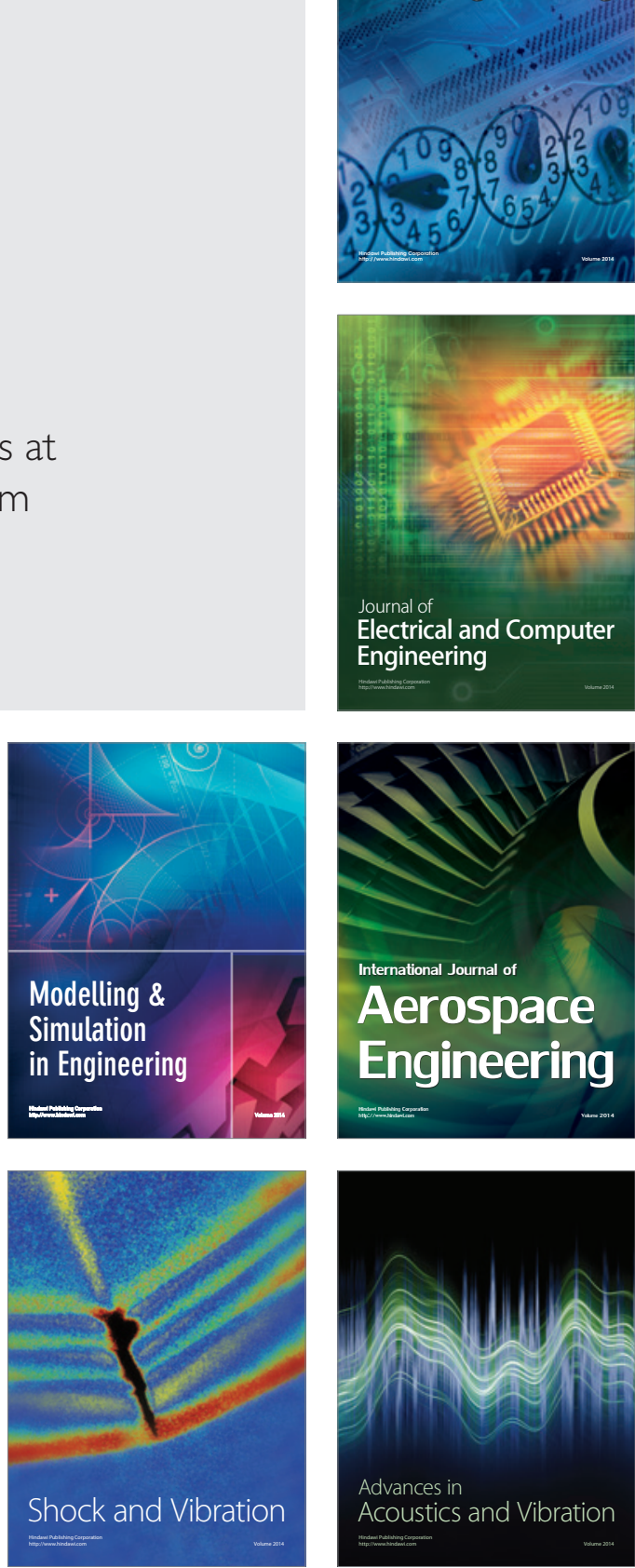